\section{Edycaçãa
Por Escrita}

ARTIGO

\title{
Um estudo reflexivo sobre o currículo na educação infantil
}

\author{
A reflective study of the curriculum in early childhood education
}

Keila Rosa dos Santos Britoa

\section{Editores}

Maria Inês Côrte Vitoria PUCRS, Brasil

Pricila Kohls dos Santos

PUCRS, Brasil

\section{Equipe Editorial}

Carla Spagnolo

PUCRS, RS, Brasil

Marcelo Oliveira da Silva

PUCRS, RS, Brasil

Rosa Maria Rigo

PUCRS, RS, Brasil

ISSN 2179-8435

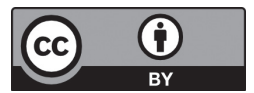

A matéria publicada neste periódico é licenciada sob forma de uma Licença Creative Commons - Atribuição 4.0 Internacional. http://creativecommons.org/licenses/by/4.0/
RESUMO: As linhas que compõe esse artigo revelam a trajetória, as diferentes concepções do Currículo da Educação Infantil seguidos de uma discussão a respeito da prática docente e de importantes revelações sobre o aprendiz dessa modalidade de ensino. O retrospecto da Educação Infantil no Brasil serviu para revelar como veio, para quê veio, para quem veio e como se deu seu processo evolutivo. $\mathrm{O}$ tópico que trouxe as diferentes concepções sobre o currículo serviu para clarear o conceito e a forma como esse instrumento vem dando sentido ao ato de educar. O último tópico que trata da prática docente e das potencialidades do aluno vem trazendo reflexões sobre a capacidade de aprendizagem, o que deve ser ensinado, de que maneira e em que ritmo, assim com também, foram expostas algumas alternativas de trabalho docente para que seja pensado um currículo como ferramenta de garantia de uma aprendizagem plena. Esse estudo procurou dar ênfase ao Currículo da Educação Infantil como objeto norteador das práticas docentes. Findada a pesquisa, conclui-se que o currículo é uma ferramenta indispensável e que precisa estar em constante adequação para que seja garantido o desenvolvimento integral da criança. Este estudo foi edificado sobre bases teóricas a partir de um estudo qualitativo de cunho exploratório.

Palavras-chave: Reflexão. Currículo. Educação Infantil.

ABSTRACT: The lines composing this article reveal the trajectory, different conceptions of the curriculum from kindergarten followed by a discussion about the teaching and practice of important revelations about the Apprentice this teaching modality. The retrospect of Early Childhood Education in Brazil served to reveal how he came to those who came and gave as its evolutionary process. The topic that brought the various conceptions of the curriculum served to clarify the concept and how this instrument has given meaning to the act of educating. The last topic that deals with the teaching practice and potential of the student is bringing reflections on the learning capacity, what should be taught, how and at what pace, so with too, were exposed some alternative teaching work to be designed a curriculum as a tool for ensuring proper learning. This study sought to emphasize the Curriculum of Early Childhood Education as a guiding object of teaching practices. Completed research, it is concluded that the curriculum is an indispensable tool that needs to be in constant adaptation to be guaranteed the full development of the child. This study was under - built theoretical bases from a qualitative study of an exploratory nature.

Keywords: Reflection. Curriculum. Early Childhood Education.

a Mestre em Ciências da Educação pela Universidade Lusófona de Humanidades e Tecnologias, Lisboa, Portugal. <keilabrito8@ gmail.com> 
O adulto, com muita fadiga, aprendeu a frear suas emoções e sensações corporais dando às mesmas uma forma discursiva, A criança, pequena, ao contrário, se contrapõe ao adulto [...], cheia de uma invasiva e escandalosa corporeidade, com necessidades corporais impelentes $[\ldots]$ - de corpo inteiro $[\ldots]$.

(SIEBERT, 1998, p. 80).

C

Tomo se sabe a educação está vivendo uma era de incertezas. O mundo está mudando e a rapidez em que o cenário muda nos força a interrogar, fazer, testar, refazer, avaliar e aplicar nossas estratégias de ensino. É nesse contexto de mudanças que o educador, principalmente o que trabalha com o público infantil, deve estar atento às suas práticas, observando se são mesmo eficazes e se garantem um ensino de qualidade.

Com base no fato de que o currículo de Educação Infantil propõe métodos e ordem que delimitam e regulam os conteúdos a serem trabalhados no âmbito escolar, procurou-se dar ênfase a essa ferramenta, de modo a compreender sua concepção, e a importância da construção de um projeto de trabalho bem pensado para o público infantil.

O tema currículo tem sido alvo de debate nos palcos de discussão sobre assuntos educacionais no Brasil e no mundo. Embora sua definição se diversifique nesse cenário de debates, Moreira (2000) afirma a existência de registros do século XVII, onde currículo se define como projeto de controle de ensino e aprendizagem.

A necessidade de compreender e discutir o currículo na Educação Infantil é oriunda dos anseios advindos da prática docente, portanto esse estudo se torna relevante na medida em que proporciona uma maior compreensão do fazer pedagógico e melhor reflexão no que há para ser ensinado à criança nos primeiros anos de vida escolar.

Compreender a criança no espaço de aprendizagem, assim como conhecer seus limites e potencialidades é tarefa indispensável para o educador compromissado com o trabalho docente, portanto, um olhar atendo, permite ao professor, eliminar do seu plano de trabalho aquelas práticas que bloqueiam os diferentes modos de pensar e agir do educando e é fundamentado nessa ideia que propomos, também, mergulhar no aprendiz e na prática docente dessa modalidade de ensino.

No decorrer do trabalho foi realizado um breve histórico da Educação Infantil no Brasil, objetivando clarear o processo evolutivo dessa Instituição de Ensino, o qual vem revelando os avanços e as conquistas alcançadas, desde o período da colonização brasileira.

Esse momento perpassou pela primeira forma de educação infantil de caráter assistencial (totalmente desprovida de fazer pedagógico), seguido da exposição da criação da Lei de Diretrizes e Bases de Educação Nacional e do Estatuto da Criança e do Adolescente como elementos fortalecedores da concepção de infância e dos direitos dos 
pequenos indefesos. Procurou-se também destacar o Referencial Curricular Nacional para Educação Infantil, como orientador do trabalho realizado nas escolas destinadas ao público infantil.

Posteriormente foram enfatizadas as diferentes concepções do currículo na Educação Infantil oriundas de diversos estudiosos do assunto, com o objetivo de elucidar a ideia de currículo e a importância desse instrumento no processo educacional da criança.

Para uma melhor compreensão do nosso objeto de estudo, dedicamos um tópico à prática docente e ao aprendiz da educação infantil. Na tentativa de contribuir com o assunto, foram acrescentadas algumas propostas de trabalho docente fundamentadas nas concepções de estudiosos desse campo, as quais foram expostas pela relevância que apresentam para o desenvolvimento do aluno de classe infantil.

O debate realizado pelos autores proporcionou um novo olhar para o que há para ser ensinado e a forma como deve ser conduzido o ensino do público infantil, com vista na formação integral do alunado dessa Modalidade de Ensino.

Diante das diferentes concepções, pode se dizer que o currículo escolar é algo indispensável e indissociável das práticas docentes isso leva a crer que não há escola sem currículo, sendo este instrumento, o eixo norteador do fazer pedagógico.

\section{O processo evolutivo da educação infantil no Brasil}

A revolução industrial e a crescente urbanização ocorrida na Europa por volta do século XIX foi um advento que mudou a vida das mulheres europeias.

Com a necessidade de ajudarem no sustento doméstico, as trabalhadoras das grandes industriais não tinham onde deixar seus filhos pequenos, o que forçou a criação de um local seguro para "guardar" sua prole - uma espécie de asilo infantil.

Com esse advento europeu, o Brasil começa a formalizar os primeiros debates rumo ao atendimento às crianças filhas de mães trabalhadoras, porém esse debate aconteceu num âmbito bem restrito (PASCHOAL; MACHADO, 2009).

De acordo com Kuhlmann Jr. (2000), embora já articulasse debates no Brasil a respeito da criação de instituições destinadas às crianças, esses asilos surgiram somente após a Lei do Ventre Livre e eram destinados às crianças filhos de escravas.

Com um caráter assistencialista e filantrópico, essa Instituição não era concebida como um direito social e seu objetivo maior era adestrar esses pequeninos.

Educação Por Escrito, Porto Alegre, v. 5, n. 1, p. 68-79, jan.-jun. 2014 
Apesar da pouca articulação, em 1875, foi criado o primeiro Jardim de Infância no Rio de Janeiro, com uma proposta pedagógica inspirada nos ideais de Froebel, esta Instituição de Ensino tinha um caráter privativo e era de alcance apenas da classe mais alta do país, assim relatam Kramer (1996), Moreira e Silva (2000).

Conforme esses relatos são percebidos no Brasil duas instituições diferentes - uma destinada aos filhos das escravas e outra destinada aos filhos da população que compunha a classe alta do país.

Nas palavras de Kuhlmann Junior: "O jardim de infância, criado por Froebel, seria a instituição educativa por excelência, enquanto a creche e as escolas maternais [...] seriam assistências e não educariam para a emancipação [...]" (1999, p. 73). Ainda de acordo o mesmo autor, no século XX, o Brasil se depara com um novo cenário e as discussões nessa direção se intensificam.

A explosão do crescimento industrial e a crescente imigração do país forçam a criação e expansão das creches com a finalidade de atender não somente os filhos das trabalhadoras das indústrias, mas também aos filhos das mulheres que trabalhavam nas casas de família. "A creche era considerada uma instituição de caráter assistencial-filantrópico de cuidado com a higiene e com a segurança física da criança" (CHAVES, 2008, p. 99). É percebido, portanto, que a criação e expansão da educação infantil são exteriores às reais necessidades da criança.

Devido à crescente evasão e repetência dos alunos do primeiro grau oriundos das classes pobre do país, foram abertas as portas para as crianças de classe baixa com idade de 4 a 6 anos, até então privada do direito à cultura. Esse tipo de educação foi instituído para amenizar a situação de fracasso escolar acorrido por causa da carência cultural advinda do seio familiar (SILVA, 2011).

Somente a partir de 1980 que foi intensificado o movimento em direção à garantia dos Direitos Humanos e junto com esses direitos está o de acesso da criança de 0 a 6 anos de idade à Educação Infantil, garantido pela SEÇ̃̃̃O II da nova Lei de Diretrizes e Bases de Educação Nacional - Lei no 9.394/96.

O Estatuto da Criança e do Adolescente, instituído pela Lei 8.069 no dia 13 de julho de 1990, vem fortalecer a concepção de infância e os direitos das crianças passam a ser garantidos. Posteriormente em 1998, é criado o Referencial Curricular Nacional para Educação Infantil, que veio trazer orientações para o trabalho realizado com as crianças de 0 a 6 anos de idade.

\section{O currículo na Educação Infantil - concepção}

Os conteúdos escolares no Brasil sofriam forte ligação com a concepção jesuítica do período colonial, o que implica dizer que reinava, nesse período, um currículo tradicional assistencialista. 
Com o embrião das crises econômicas do inicio do século XX, provocada pela Primeira Guerra Mundial, a educação assume um caráter emergencial de ser um poderoso instrumento de reconstrução política, moral e social.

O cenário mundial, nesse período, provocava crescente preocupação em estudiosos do assunto, a exemplo disso, os autores americanos John Dewey e Kilpatrick apresentavam profundas críticas sobre o currículo tradicional, e junto com elas, traziam novas ideias de um currículo fundamentado em ideais progressistas (BIN, 2012).

O currículo da Educação Infantil é, portanto, mais jovem em relação às outras modalidades de ensino, e se diferencia dos demais por levar em consideração o fato de que essa Instituição de Ensino deve ser um espaço de cuidados educacionais com crianças nos seus primeiros anos de vida, sendo esta etapa da vida onde a criança tem o primeiro contato com o conhecimento.

É importante frisar os objetivos e as funções sociopolíticas e pedagógicas das escolas infantis tomando como base as novas Diretrizes Curriculares Nacionais para a Educação Infantil - DCNEIs:

Art. $7^{\circ}$ Na observância destas Diretrizes, a proposta pedagógica das instituições de Educação Infantil deve garantir que elas cumpram plenamente sua função sociopolítica e pedagógica:

I - oferecendo condições e recursos para que as crianças usufruam seus direitos civis, humanos e sociais; II - assumindo a responsabilidade de compartilhar e complementar a educação e cuidado das crianças com as famílias;

III - possibilitando tanto a convivência entre crianças e entre adultos e crianças quanto a ampliação de saberes e conhecimentos de diferentes naturezas;

IV - promovendo a igualdade de oportunidades educacionais entre as crianças de diferentes classes sociais no que se refere ao acesso a bens culturais e às possibilidades de vivência da infância;

$\mathrm{V}$ - construindo novas formas de sociabilidade e de subjetividade comprometidas com a ludicidade, a democracia, a sustentabilidade do planeta e com o rompimento de relações de dominação etária, socioeconômica, étnico-racial, de gênero, regional, linguística e religiosa. (BRASIL, 2009)

Portanto, quando se pensa na construção de um currículo para a Educação Infantil, deve se pensar na construção de um sujeito social e histórico em um espaço que possibilite a integração entre os diferentes aspectos do desenvolvimento humano. Mas afinal, o que é currículo? "Currículo é uma obra que está a meio caminho entre o texto puramente teórico e o manual de atividades, configurando-se como instrumento de apoio à organização da ação escolar e, sobretudo à atuação dos professores" (KRAMER, 2001, p. 14). 
Retomando a definição desse termo, as Diretrizes Curriculares Nacionais para a Educação Infantil, definem:

Art. $3^{\text {o }}$ O currículo da Educação Infantil é concebido como um conjunto de práticas que buscam articular as experiências e os saberes das crianças com os conhecimentos que fazem parte do patrimônio cultural, artístico, ambiental, científico e tecnológico, de modo a promover o desenvolvimento integral de crianças de 0 a 5 anos de idade. (BRASIL, 2009, p. 1)

Entende-se que o processo de fabricação do currículo é um processo social construído por fatores lógicos, epistemológicos, intelectual. Nesse sentido pode-se dizer que o currículo não é neutro e nem abstrato eles produzem valores, sentido e significados ele transmite as necessidades e os conhecimentos que a sociedade mais valoriza no momento sendo, portanto, uma forma de conhecimento social.

A respeito de currículo, Nascimento (2007), esclarece:

[...] o currículo não pode ser vivido como uma listagem de objetivos e conteúdos a serem atingidos. $\mathrm{O}$ currículo é algo vivo e dinâmico. Ele está relacionado a todas as ações que envolvem a criança no seu dia-a-dia dentro das instituições de ensino, não só quando nós professores consideramos que as crianças estão aprendendo. O currículo deve prever espaço de interações entre as crianças sem a mediação direta do professor, e espaços de aprendizagem na interação com os adultos, nos quais as crianças sejam as protagonistas. (NASCIMENTO, 2007, p. 16)

Pensar em currículo para a Educação Infantil é pensar sobre a identidade dessas crianças, como elas aprendem, e como se desenvolvem assim como as necessidades e interesses desses pequeninos. Além disso, a construção do currículo deve passar pela questão que norteia as escolhas vinculadas à proposta Pedagógica.

O currículo não deve atrapalhar o processo de ensino aprendizagem e para isso o professor deve estar atento à intenção do conteúdo a ser ministrado, se está ou não, dificultando o aprendizado por causa de sua excessiva extensão, assim como avaliar constantemente o método utilizado, procurando ajustando suas ações para que seja favorecido o desenvolvimento contínuo do aluno.

\section{A prática docente e 0 aprendiz da educação infantil}

A presença das crianças nas salas de aula, ainda é mal compreendida por muitos professores de Educação Infantil. Pode-se dizer que ainda existe uma forte concepção de que esses pequeninos se desenvolvem de forma natural, 
orgânica, bastando, portanto, assessorá-los nas suas necessidades básicas para que seja garantido o desenvolvimento pleno.

De acordo com os apontamentos de alguns estudiosos, não basta somente dar assistência a essas crianças é importante que sejam oferecidas condições necessárias para que cresçam e aprendam. Nas palavras de Oliveira:

[...] em relação à aprendizagem infantil considera que as habilidades para a criança discriminar cores, memorizar poemas, representar uma paisagem através de um desenho, consolar um coleguinha que chora etc., não são fruto de maturação, mas são produzidas nas relações que as crianças estabelecem com o mundo material e social, mediadas por parceiros diversos [...]. (OLIVEIRA, 2010, p. 5-6)

De acordo com a autora supracitada, na Educação Infantil, a aprendizagem se faz por meio das relações que a criança estabelece com o professor e com os colegas de sala de aula, e para que isso aconteça de forma positiva, o professor deve proporcionar esse ambiente de interação.

É, portanto nesse sentido que pesquisadores como: Rossetti-Ferreira, Amorim e Oliveira 2009 vêm mostrando a necessidade de planejamento e acompanhamento do pedagógico nessa fase de ensino.

Nesse contexto de reconhecimento de uma maior profissionalização do trabalho pedagógico, a Educação Infantil não deve ser tida, como um mero lugar de apoio a crianças pequenas, mas, deve ser tida como um lugar de formação humana.

A criança precisa ser tocada "de modo a promover mudanças importantes em seu comportamento, na visão de mundo, no modo de se expressar" (AUGUSTO, 2013, p. 20).

A importância de um currículo que promova o desenvolvimento integral da criança não deve guiar as práticas pedagógicas para um fazer burocrático e com poucos desafios. De acordo com Augusto (2013):

Atividades com pouco ou nenhum desafio, como preencher fichas de tarefas simples, ligar pontos, colorir desenhos prontos etc.; conhecer uma grande quantidade de informações extraídas dos livros, sem conversar com os colegas sobre os sentidos que isso tem para cada um; longos períodos de espera conduzidos de forma heterônoma pelos adultos; exercícios repetitivos de coordenação motora, preparatórios de alfabetização, entre outros, são alguns exemplos de vivências que comumente não constituem uma experiência transformadora. (AUGUSTO, 2013, p. 20)

A concepção de muitos educadores dessa modalidade de ensino está fincada nessas propostas de trabalho, o que faz com que sua prática docente, além de estar desprovida de sentidos para a criança pequena, pouco contribui para seu desenvolvimento enquanto profissional e consequentemente desqualifica o fazer pedagógico. 
A autora supracitada nos remete ao fato de que a criança deve aprender em si mesma. Através de suas próprias experiências essa criança pode ter um aprendizado em constante movimento na medida em que recupera a experiência adquirida em outras situações, e para isso deve se pensar em práticas eficientes, em currículo adequado.

Em conformidade com essa afirmação, as Diretrizes Curriculares Nacionais para Educação Infantil art. 3º, define o currículo como:

[...] conjunto de práticas que buscam articular as experiências e os saberes das crianças com os conhecimentos que fazem parte do patrimônio cultural, artístico, ambiental, científico e tecnológico, de modo a promover o desenvolvimento integral de crianças de 0 a 5 anos de idade. (BRASIL, 2009)

De acordo com a definição, entende-se que a experiência se refere aos saberes que são construídos ao longo da vida, nesse sentido entende-se que os saberes da criança devem ser contemplados no planejamento do professor para serem articulados com novos conhecimentos.

As novas experiências podem ser adquiridas pelos educandos a partir de atividades potencializadoras em ambiente coletivos especialmente destinados a elas. Em se tratando da ênfase à experiência: "a experiência está circunscrita por condições de interação, de diversidade e de continuidade", Augusto (2013, p. 22). A respeito da condição de interação Oliveira escreve que:

A ideia de interação social é assim aproximada da noção de ação conjunta, da relação Eu/Outro, em que sentidos são construídos sempre em resposta a uma alteridade. Mas tal noção vai além disso e abrange o social enquanto aparato histórico e ideológico, enquanto conjunto de normas, valores, representações. (OLIVEIRA, 2011 p. 22).

Nessa concepção, o homem se firma como produto do meio e essa perspectiva é focada na experiência simbólica determinada pela cultura, pelas relações interpessoais.

A segunda condição, que é de diversidade de experiências é fundamentada no art. 9º inciso V das Diretrizes Curriculares Nacional para Educação Infantil, o qual aponta para a necessidade de inserir no currículo, ações que proporcione um aprendizado significativo, que pode ser garantida através da "participação das crianças nas atividades individuais e coletivas". 
De acordo com as Diretrizes Curriculares Nacionais para Educação Infantil - DCNEI, as práticas pedagógicas devem ser voltadas para a interação dos educandos, com o mundo, com o meio e com as pessoas que os cercam. O ambiente facilitador de aprendizagem é fundamental para que o aluno da Educação Infantil adquira as experiências necessárias na sua idade. É no cotidiano da escola que deve ser facilitado a "curiosidade a exploração, o encantamento, o questionamento, a indagação e o conhecimento das crianças em relação ao mundo físico e social, ao tempo e à natureza" (BRASIL, 2009, art. 9º, inciso VIII).

Em relação à continuidade da experiência, esta exige uma reflexão sobre o critério estabelecido para o tempo durante a elaboração do planejamento. O acúmulo de atividades, pode não desenvolver um aprendizado significativo, portanto é necessário que seja respeitado o ritmo dessa faixa etária, assim como o tempo necessário para que a criança possa apropriar-se dos procedimentos e sistematizar o conhecimento.

É necessário interrogar-se sobre como as crianças vivenciam os aspectos dinâmicos do contexto educativo e que são determinados pela sucessão dos episódios, pela sua recorrência no decorrer do dia, pelo ritmo geral, pelas modulações das várias dimensões; aspectos dinâmicos do contexto educativo que, em um jogo de oscilações entre a continuidade e a descontinuidade, se traduzem em uma vivência que se articula entre o polo do familiar, do habitual e do previsível, e o polo do inédito, do inesperado e do estimulante (NIGITO, 2004, p. 44).

Diante dos expostos, compreende-se a necessidade de um pensar reflexivo sobre o currículo norteador da prática docente, de modo que seja possível, um trabalho específico e próprio para esse público tão especial.

\section{Considerações finais}

A criança começa o aprendizado muito cedo. Um bebê, por exemplo, já é um observador das coisas ao seu redor. Com base no estudo realizado, pode-se dizer que a vivência no ambiente doméstico ou em outro lugar, não é a mesma que se tem no espaço da Educação Infantil o que requer maior responsabilidade, do educador, em conduzir esse aprendizado.

No momento escolar a criança observa os aspectos da escrita, da fala, é o momento de interação com a linguagem. Da mesma forma o aluno da Educação Infantil desenvolve linguagens artísticas, pintura, música, teatro, etc.. Nesse sentido o educador deve conduzir seu fazer pedagógico para que seja garantida uma aprendizagem significativa. 
Estabelecer tempo mais estável pode ser uma atitude interessante, pois pode desenvolver hábitos e comportamentos específicos e uma maior familiaridade com as práticas educativas como: roda para conversa, roda de leituras, momento da alimentação etc.

Da mesma forma, enfatizar a importância de respeitar o tempo do colega na sala de aula, ou seja, respeitar o momento e o ritmo do outro, isso é fundamental para o desenvolvimento de atitude de respeito e companheirismo.

É importante destacar que o professor, também aprende nesse ambiente de aprendizagem, pois é no contexto de interações que acontece o desenvolvimento pessoal e profissional é através desse ambiente que o educador, questiona, testa, cria, confirma, aprecia e transforma.

Os momentos de coletividade entre as crianças devem ser contemplados com trabalhos diversificados que proporcione o enriquecimento de saberes na mesma medida em que proporcione a capacidade de lidar com os conflitos causados pelas diferenças.

Entende-se, portanto, que o Currículo da Educação Infantil deve provocar vínculos afetivos e que amplie suas capacidades de comunicação e interação social, atitudes de ajuda e colaboração.

Portanto, o brincar e as diferentes linguagens utilizadas em sala de aula se tornam ferramentas indispensáveis na composição curricular, pois é através da brincadeira e das diferentes expressões (corporal, musical, oral), que a criança expressa suas emoções, pensamentos, sentimentos, desejos e suas necessidades. É, portanto nesse momento que a criança começa a compreender e ser compreendido.

Nesse sentido entende-se que as experiências adquiridas pelo educador, em sala de aula, devem ser concebidas como um processo necessário, para que seja exercida uma boa revisão das programações do ciclo da Educação Infantil e consequentemente de reformulação das propostas curriculares de modo que a proposta curricular venha proporcionando autonomia e confiança para que a criança tenha condições de interagir no mundo complexo em que vivemos.

Com base na pesquisa a respeito do currículo na educação infantil, percebe-se que os conteúdos a serem trabalhados com o público infantil, devem ser pensados, elaborados, e bem projetados para que seja garantido um aprendizado significativo.

Um bom currículo deve considerar a criança como um ser sócio- histórico e o professor por sua vez deve estar atento aos objetivos propostos pelo currículo de modo que, se não alcançados, devem ser repensados e reformulados.

Mediante o que está posto nesse trabalho, pode-se afirmar que essa pesquisa além de contribuir para uma reflexão a respeito do ofício profissional dentro da escola, assume também uma posição de suporte que ajudará o educador a usar estratégias enriquecedoras para o trabalho com o público infantil. 


\section{Referências}

AUGUSTO, S. de O. A experiência de aprender na Educação Infantil. In: Novas Diretrizes para a Educação Infantil. Salto para o futuro, ano XXIII, n. 9, jun. 2013.

BIN, A. C. Concepções de conhecimento e Currículo em W. Kilpatrick e implicações do Método de projetos. 2012.120 p. (Mestrado em Educação) - Faculdade de Educação, Universidade de São Paulo, São Paulo, 2012.

BRASIL. Estatuto da Criança e do Adolescente. Lei no 8.069/90, de 13 de junho de 1990.

BRASIL. Lei de diretrizes e Bases da Educação Nacional. Lei no 9.394/96, de 20 de dezembro de 1996.

BRASIL. Ministério da Educação e do Desporto. Secretaria de Educação Fundamental. Referencial Curricular Nacional para a Educação Infantil. Documento Introdutório. Brasília: MEC/SEF, 1998. Vol. 1.

BRASIL. Ministério da Educação. Conselho Nacional de Educação. Câmara de Educação Básica. Resolução CNE/CEB n. 5, de 17 de dezembro de 2009. Institui as Diretrizes Curriculares Nacionais para a Educação Infantil. Diário Oficial [da] República Federativa do Brasil, Brasília, DF, 18 dez. 2009. Seção 1, p. 18.

BRASIL. Conselho Nacional de Educação. Resolução CNE/CEN no 05/09. Revisão das Diretrizes Curriculares Nacionais para a Educação Infantil (DCNEI), 2009.

CHAVES, G. M. M. Ação pedagógica na creche, Porto Alegre, n. 43, p. 99-105, jan.-jun. 2008. Disponível em: <http://www1.fapa. com.br/cienciaseletras/pdf/revista43/artigo7>. Acesso em: 26 out. 2013.

KUHLMANN JR, M. Educação Infantil e Currículo. In: FARIA, A. L. G.; PALHARES, M. S. Educação infantil pós LDB: rumos e desafios. São Paulo: Autores Associados, 1999. p. 51-56.

KUHLMANN JR, M. Educando a infância brasileira. In: LOPES, E. M. T.; FARIA FILHO, L. M.; VEIGA, C. G.; (Org.). 500 anos de educação no Brasil. Belo Horizonte: Autêntica, 2000. p. 469-496.

KRAMER, Sonia. Pesquisando infância e educação: um encontro com Walter Benjamin. In: KRAMER, Sonia; LEITE, M. I. (Org.). Infância: Fios e desafios da pesquisa. Campinas: Papirus, 1996. p. 13-38.

KRAMER, Sonia (Org.). Formação de profissionais de educação infantil no Estado do Rio de Janeiro. Relatório de Pesquisa. Rio de Janeiro: Ravil, 2001.

MOREIRA, A. F. B.; SILVA, T. T. da (Org.). Currículo, cultura e sociedade. Tradução de Maria Aparecida Baptista. 4. ed. São Paulo: Cortez, 2000.

NASCIMENTO, A. M. Currículo e práticas pedagógicas na educação infantil. Revista Criança do Professor de Educação Infantil, Brasília, n. 43, p. 14-17, ago. 2007.

NIGITO, G. Tempos institucionais, tempos de crescimento: a gestão do cotidiano dos pequenos, dos médios, dos grandes na creche. In: BONDIOLI, Anna (Org.). O tempo no cotidiano infantil, perspectivas de pesquisa e estudos de casos. São Paulo: Cortez, 2004. p. $43-103$ 
OLIVEIRA, Z. M. R. Jogo de papéis: um olhar para as brincadeiras infantis. São Paulo: Cortez, 2011. Vol. 1. 156 p.

OLIVEIRA, Z. M. R. O currículo na Educação Infantil: o que propõem as novas diretrizes Nacionais? In: BRASIL. Ministério da Educação e da Cultura, Conselho Nacional de Educação, Câmara de Educação Básica. Disponível em: <http://portal.mec.gov.br/index. php?option=com_content\&view=article\&id=15860\&Itemid=1096>. Acesso em: 06 maio 2014.

PASCHOAL, J. D.; MACHADO, M. C. G. A história da Educação Infantil no Brasil: avanços, retrocessos e desafios dessa modalidade educacional, Revista HISTEDBR On-line, Campinas, n. 33, p. 78-95, mar. 2009.

ROSSETTI-FERREIRA, M. C.; AMORIM, K. de S.; OLIVEIRA, Z. de M. R. de. Olhando a criança e seus outros: uma trajetória de pesquisa em educação infantil. Revista de Psicologia, São Paulo: USP, v. 20, n. 3, p. 437-464, jul.-set. 2009.

SIEBERT, R. O adulto frente à criança: ao mesmo tempo igual e diferente. In: BONDIOLI, Anna; MANTOVANI, Susanna. Manual de educação infantil: de 0 a 3 anos - uma abordagem reflexiva. 9. ed. Porto Alegre: Artmed, 1998. p. 77-87.

SILVA, D. D. A prática docente reflexiva: o currículo na educação infantil. Rio de Janeiro: Três Rios, 2011. Disponível em: <http:// www.redentor.inf.br/arquivos/pos/publicacoes/31052012DANIELE_DUTRA_SILVA.pdf>. Acesso em: 10 mar. 2014.

\section{Endereço para correspondência:}

Keila Rosa dos Santos Brito

Rua Antônio Coelho da Silva, 66 - Centro

68380-000 São Félix do Xingu, PA, Brasil

E-mail:<keilabrito8@gmail.com>

Recebido em: abril/2014

Aceito em: maio/2014 